\title{
Intracytoplasmic Re-localization of miRISC Complexes
}

\author{
Bünyamin Akgül* and Ijpek Erdoğan \\ Non-coding RNA Laboratory, Department of Molecular Biology and Genetics, Izmir Institute of Technology, Urla, Turkey
}

MicroRNAs (miRNAs) are a conserved class of non-coding RNAs of 22 nucleotides that post-transcriptionally regulate gene expression through translational repression and/or mRNA degradation. A great progress has been made regarding miRNA biogenesis and miRNA-mediated gene regulation. Additionally, an ample amount of information exists with respect to the regulation of miRNAs. However, the cytoplasmic localization of miRNAs and its effect on gene regulatory output is still in progress. We provide a current review of the cytoplasmic miRNA localization in metazoans. We then discuss the dynamic changes in the intracytoplasmic localization of miRNAs as a means to regulate their silencing activity. We then conclude our discussion with the potential molecules that could modulate miRNA localization.

Keywords: microRNA, localization, polysome, mRNP, translational repression

\section{OPEN ACCESS INTRODUCTION}

Edited by:

Laurence Amar,

Centre National de la Recherche Scientifique (CNRS), France

Reviewed by:

Pabitra Sahoo,

University of South Carolina,

United States

Edward K. L. Chan,

University of Florida, United States

*Correspondence:

Bünyamin Akgül bunyaminakgul@iyte.edu.tr

Specialty section:

This article was submitted to

$R N A$,

a section of the journal

Frontiers in Genetics

Received: 31 July 2018 Accepted: 03 September 2018 Published: 20 September 2018

Citation:

Akgül B and Erdoğan i (2018) Intracytoplasmic Re-localization of miRISC Complexes.

Front. Genet. 9:403.

doi: 10.3389/fgene.2018.00403
MicroRNAs (miRNAs) are an important group of non-coding RNAs (ncRNAs) of 17-22 nt in length that regulate gene expression post-transcriptionally typically by binding to the $3^{\prime}$ untranslated regions (UTR) of mRNAs (Bartel, 2018). The first example of miRNAs, lin-4, was identified in C. elegans during a screen for genes that are important for developmental timing (Lee et al., 1993; Wightman et al., 1993). Expressed in a variety of species ranging from viruses to primates (Griffiths-Jones et al., 2006), miRNAs are now recognized as micromanagers of post-transcriptional gene expression both in development and diseases (Bartel and Chen, 2004).

In the canonical pathway (Figure 1), miRNA genes are transcribed by RNA polymerase II with a $5^{\prime}$ cap and a $3^{\prime}$ tail (Lee et al., 2004). The first processing step takes place in the nucleus where the primary miRNA transcript is trimmed into a stem-loop structure by Drosha (Lee et al., 2003). The stem-loop structure with a 2 nt overhang is then transported to the cytoplasm through Exportin-5 (Lund et al., 2004) where it is converted into a $22 \mathrm{nt}$ duplex by Dicer (Chendrimada et al., 2005). The strand with the more unstable $5^{\prime}$-end is usually selected for loading onto miRNAinduced silencing complex (miRISC) (Iwasaki et al., 2010). miRISC is a microribonucleoprotein complex that are composed of AGO proteins, glycine-tryptophan protein of $182 \mathrm{kDa}$ (GW182) and some other proteins (Krol et al., 2010). Based on the complementarity between the miRNA and its target, RISC-bound miRNAs induce target RNA degradation and/or translational suppression (Yekta et al., 2004; Filipowicz et al., 2008). The carboxy-terminal part of GW182 is involved in the recruitment of poly A binding protein (PABP) and the deadenylases CCR4 and CAF1. mRNA degradation is initiated through deadenylation by the PAN2-PAN3 and CCR4-NOT complexes followed by DCP2-mediated decapping and degradation by the $5^{\prime}-3^{\prime}$ exonuclease XRN1 (Jonas and Izaurralde, 2015). In this process, GW182/TNRC6 proteins coordinate interactions between AGOs and the PAN2-PAN3 and CCR4-NOT complexes. The CCR4-NOT complex may also induce translational repression but the repression may also involve the release of eIF4A1 and eIF4A2 from target mRNAs (Fukao et al., 2014; Fukaya et al., 2014). miRISCs contain a number of additional factors that might modulate miRNA activity or miRISC localization (Zhang et al., 2007; 
Krol et al., 2010). miRNAs may also be generated through alternative pathways, such as Drosha-DGRC8-independent and TUTase-dependent pathways (Yang and Lai, 2011). In this review, we will discuss miRNA localization, focusing on polysomal association and re-distribution of polysome-associated miRNAs as a means to regulate miRNA silencing activity.

\section{miRNA LOCALIZATION}

miRNAs, miRNA-targeted mRNAs and associated proteins were traced to determine the intracellular location of miRISCs. Earlier studies that involved injection of labeled miRNAs or in situ hybridization revealed that miRISC is primarily localized in the cytoplasm (Pillai et al., 2005; Bhattacharyya et al., 2006). The use of luciferase reporter mRNA with miRNA binding sites showed localization of target mRNA to processing bodies (PBs) in a miRNA-dependent way (Liu et al., 2005; Pillai et al., 2005). These studies also detected AGO proteins in the cytoplasm, clearly documenting the cytoplasmic localization of tested miRNAs, their targets and associated proteins. Considering the fact that miRNA maturation and loading onto AGO proteins occur in the cytoplasm, the cytoplasmic localization of miRISC has been widely accepted as a general rule of thumb. $\mathrm{P}$ bodies, stress granules (SGs), multivesicular bodies (MVBs), endoplasmic reticulum (ER) and mitochondria are considered to house miRISCs in the cytosol (Leung, 2015). Interestingly, genomewide small RNA profiling studies demonstrated that mature miRNAs exist in the nucleus and associate with AGO proteins (Meister et al., 2004; Jian-You et al., 2010; Jeffries et al., 2011). We will primarily focus on the cytoplasmic re-arrangement of miRISC and thus refer the readers to the excellent reviews that deal with nuclear functions of miRNAs (Catalanotto et al., 2016; Liu et al., 2018).

\section{NON-MEMBRANEOUS CYTOPLASMIC $\mathrm{FOCI}$}

Cytoplasm contains various non-membraneous compartments that may serve as important sites for RNA biology, including miRNA-mediated gene regulation. Among the best characterized non-membraneous compartments are PBs, SGs, germ granules, and neuronal granules (Figure 1).

Processing bodies, which contain various proteins associated with mRNA decay, translational control and RNA interference, were termed based on their content of proteins to carry out decapping of mRNAs (Sheth and Parker, 2003). Both AGO

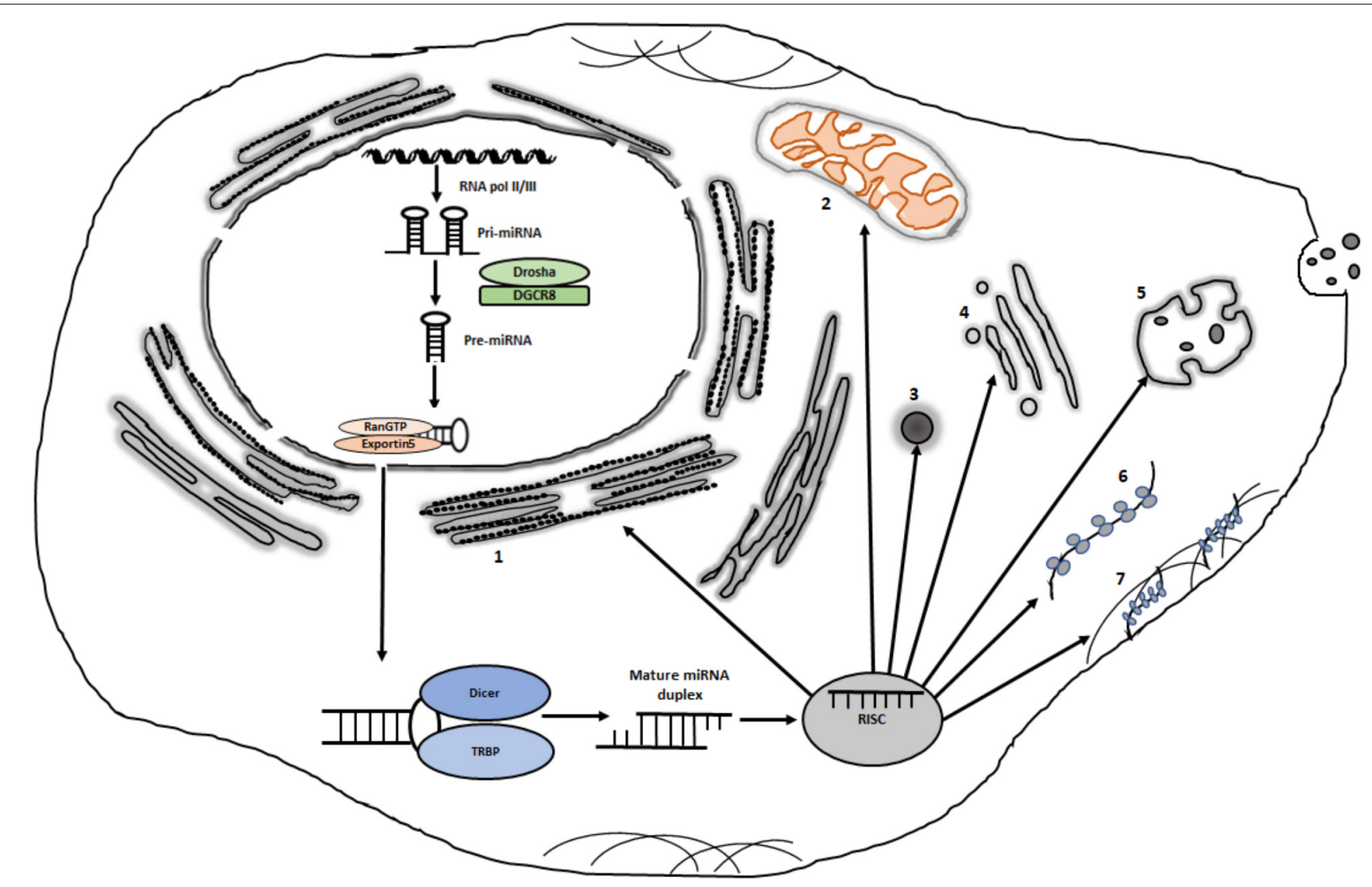

FIGURE 1 | Potential intracytoplasmic destinations of miRISCs. Following transcription and processing in the nucleus, some miRISCs are destined for the nucleus (not shown). Cytoplasmically localized miRISCs can be localized in distinct sites such as: (1) rough endoplasmic reticulum; (2) mitochondria; (3) various types of messenger ribonucleoprotein granules such as P bodies and stress granules; (4) golgi; (5) multivesicular bodies; (6) free polysomes and (7) cytoskeleton-bound polysomes. Organelles and complexes are not drawn to scale. 
and GW182 proteins co-localize with PBs (Liu et al., 2005). In earlier studies on EGFP-AGO2-transfected cells under non-physiological forced expression conditions, approximately $1.3 \%$ of the total fluorescence intensity stemmed from PBs (Leung et al., 2006), suggesting the existence of other sites for miRNA-mediated translational repression or mRNA decay (Leung and Sharp, 2013). Although these data point to the possibility that PBs are probably not the sole sites of action for miRNA-mediated gene regulation, a plethora of evidence exists for $\mathrm{PBs}$ as storage sites of miRNA targets (Bhattacharyya et al., 2006; Krol et al., 2010; Jonas and Izaurralde, 2015). Although the absence of poly(A) tails in PB-stored mRNAs questions the involvement of PBs in miRNA-mediated storage of target mRNAs and their subsequent translation (Aizer et al., 2014), a fluorescenceactivated particle sorting of endogenous $\mathrm{PBs}$ provided strong evidence for GW182-dependent, AGO2-mediated translational repression in $\mathrm{P}$ bodies (Hubstenberger et al., 2017).

Stress granules are messenger ribonunleoprotein (mRNP) granules that include mRNAs stalled in translation initiation or disassembling from polysomes (Protter and Parker, 2016). Thus, stress granules are characterized by the presence of translation initiation factors and RNA-binding proteins as well as 40S ribosomal subunits (Anderson and Kedersha, 2008). Stress granules are formed mainly under stress conditions as an adaptive response by temporary and global stall in translation of cellular mRNAs with the aim of optimizing RNA metabolism toward damage repair (Ron and Walter, 2007). One can then hypothesize that miRNA-mediated translationally blocked mRNAs could potentially end up in SGs until the stress invoking condition goes away. In fact, two important components of SGs, fragile $\mathrm{X}$ mental retardation protein and PABP1, interact with the miRNA machinery (Jin et al., 2004; Moretti et al., 2012). Along this line, quantitative analysis of the kinetics of AGO2 localization revealed that $\mathrm{AGO} 2$ is normally distributed diffusely in the cytoplasm under physiological conditions but is recurited into newly formed SGs under stress conditions (Leung et al., 2006). However, more studies are required to delineate the fate of AGO-interacting mRNAs in the SGs.

Germ granules are another example of mRNP granules that are primarily associated with germ cell lineage functions (Gallo et al., 2008). miRISC components are known to co-purify with germ granule proteins (Wu et al., 2017). Interestingly, mRNP formation in germ granules involves scanning and recognition of target sites by miRISC followed by CCR4-NOT recruitment and particle nucleation. Neuronal granules are also a type of RNP granules that are formed in neurons as transport granules since neurons require long-distance transport of mRNAs along axons and dentrites (Kiebler and Bassell, 2006). The fact that translation of mRNAs is suppressed during the transport of mRNAs to their destination (Krichevsky and Kosik, 2001) raises the possibility that these mRNAs could be translationally stalled by miRISCs. Fragile $\mathrm{X}$ mental retardation protein is a key component of neuronal granules (Kiebler and Bassell, 2006) and its interaction with miRNAs and RISC suggests the localization of at least some miRNAs in neuronal granules (Zalfa et al., 2006).

\section{ENDOMEMBRANE AND MITOCHONDRIA FOR MIRNA ACTION}

Because SGs, germ granules, and neuronal granules are formed under special conditions or in special cell types and $\mathrm{P}$ bodies are not the sole sites of miRISCs in the cytoplasm, there must be other cytoplasmic foci that harbor miRISC complexes. Such potential foci are, but not limited to, endomembranes that include ER, golgi, and MVBs in addition to a non-membraneous organelle, mitochondria (Kim et al., 2014).

As an organelle specialized in protein translation, ribosomes on rough ER translates ER-bound proteins, which are docked onto the rough $\mathrm{ER}$ through the recognition of $\mathrm{N}$-terminal signal peptides during active translation by the signal recognition particle (SRP) localized on the ER (Schwartz, 2007). ER could house at least the miRNAs that regulate gene expression at the protein translation level. In fact, serum starvation triggers the assembly of a number of miRISCs on polysomebound mRNAs in Drosophila S2 cells and some of these miRISCs sediment together with the ER component (Wu et al., 2013). Also, the AMP1 gene in Arabidopsis modulates miRNA-mediated gene expression and it is localized on the rough ER together with AGO1 (Li et al., 2013). A recent work by Sahoo et al., showed that annulate-lamellae-associated Nup358, which is a nucleoprotein, binds to AGO proteins and facilitates mRNA:miRISC intereaction through its SUMOinteracting motifs (Sahoo et al., 2017). Although Nup358 depletion has no detectable effect on AGO2 localization to rough ER, Nup358-positive annulate-lamellae structures are associated with $\mathrm{PBs}$ and SGs, indicating a potential role for annulate lamella in coordinating the cytoplasmic face of miRISCs. We would like to refer the readers to an excellent review by Kim et al. (2014), on connections between miRNAmediated silencing and endomembranes that include ER, endosomes, MVBs, lysosomes, autophagosomes, vacuoles and golgi. Multivesicular bodies are the last stage of endosomes involved in the trafficking of molecules to lysosomes, plasma membrane or golgi for various purposes. Interference with the assembly or turnover of MVBs affects miRNA-mediated regulation, suggesting a potential role for MVBs in miRISC dynamics (Gibbings et al., 2009). Considering the importance of exosome-bound miRNAs in regulating gene expression in the recipient cells (Janas et al., 2015), MVBs could play a central role in the assembly and sorting of exosome-bound miRNAs. It remains to be unraveled how miRNAs are specifically targeted into late endosomes and more importantly what determines the cytoplasmic fate of late endosomes that contain different miRNA cargos.

An interesting site for the nuclear-encoded miRNAs is mitochondria (Kren et al., 2009). Both pre-miRNAs and mature miRNAs exist in mitochondria, suggesting the mitochondrial existence of miRNA biology (Barrey et al., 2011). However, only a fraction of miRNAs exist in mitochondria and they mainly coordinate mitochondria-related functions such as mitochondria morphology, mitochondrial metabolism and cell death (Li et al., 2012). 


\section{POLYSOMAL AND NON-POLYSOMAL SITES FOR MIRNA ACTION}

The cellular translation machinery may be fractionated into different types of sub-fractions based on their translational status by taking advantage of sucrose-density fractionation (Tu and Akgül, 2005). In this approach, the cytosolic complexes are fractionated based on their molecular weight through centrifugation on a sucrose density gradient. Such a fractionation typically yields four sub-fractions, which are (1) translationally silent mRNP; (2) 40S/60S ribosomal subunits; (3) $80 \mathrm{~S}$ monosomes, and (4) polysomes.

Polysomes are formed during active translation through the sequential assembly of ribosomes on mRNAs. Non-polysomal mRNA complexes typically carry less than two ribosomes while polysomes carry two or more ribosomes. Considered as the cellular translation machinery, polysomes are classified into three groups based on their intracytoplasmic location (1) free polysomes; (2) ER-bound polysomes, and (3) cytoskeletonbound polysomes (Reid and Nicchitta, 2015). Accordingly, each type of polysome synthesizes different types of mRNAs. For example, free polysomes are involved in the translation of cytosolic proteins whereas cytoskeleton-bound polysomes primarily translate asymmetrically distributed mRNAs that are enriched in a subcellular location (Lerner et al., 2003).

Taking into account the fact that miRNA-mediated regulation partially involves translational repression and translationcoupled mRNA decay, the polysome-bound state of a miRNA could provide valuable information about its potential regulatory function. More importantly, recycling miRISCs between polysome-bound and non-polysome-bound (e.g., messenger ribonucleoprotein) target mRNA could be a potential regulatory mechanism. Although it has been challenging to uncouple mRNA degradation from translational repression, ribosome profiling has been used to demonstrate mRNA degradation to have the dominant effect in post-embryonic cells (Guo et al., 2010; Eichhorn et al., 2014). It is also widely accepted that miRNAs suppress translation at early points following their expression (Filipowicz et al., 2008). In fact, when a miRNA is over-expressed, translational repression precedes mRNA degradation (Béthune et al., 2012). However, by the time the full miRNA-mediated repression is manifested, mRNA destabilization takes over the silencing effect. Quantitative studies in mammalian cells showed that $6-26 \%$ of the repression occurs through translational repression without any contribution from mRNA degradation (Eichhorn et al., 2014). However, counting in the translationcoupled mRNA degradation, this percantage could be higher. On the other hand, miRNA-mediated silencing involves translation repression in embryos (Bazzini et al., 2012), suggesting that the consequence of miRNA repression is different in embryos probably due to the context of post-transcriptional regulatory mechanisms unique to embryos.

Polysome association of miRNAs was reported as early as 1999 (Olsen and Ambros, 1999). Later polysomal association of miRNAs has been reported in various mammalian cell types (Kim et al., 2004; Maroney et al., 2006; Nottrott et al., 2006; Petersen et al., 2006). However, not all miRNAs sediment with polysomes (Nelson et al., 2004), suggesting the presence of
miRNAs on non-polysomal mRNPs. Disassembly of polysomes as a result of translational repression triggers the formation of mRNP complexes that sequester mRNAs in a translationally inactive state. P bodies and SGs (and probably neuronal granules and germ granules) are examples of such mRNPs that serve as a hub for sorting of mRNAs for their subsequent fates. It is widely accepted now that there is a functional link among polysomes, SGs and PBs (Protter and Parker, 2016; Chantarachot and BaileySerres, 2018). Re-arrangement, then, of the miRISC localization between different types of polyribosomes and mRNPs could be a regulatory mechanism to control miRISC activity. In fact, a switch between polysomes and exosomes has been proposed as a regulatory process in which miRISC localization is used to modulate miRNA silencing capacity. In this example, polysome association of miRNAs results in an impaired miRNA export, suggesting a potential regulatory mechanism that might involve re-arrangement of miRNA localization between exosomes and polysomes (Ghosh et al., 2015).

The long-standing dispute over miRNA-mediated translational repression at the translation initiation versus elongation has been resolved in favor of translation initiation (Pillai et al., 2005; Chu and Rana, 2006; Petersen et al., 2006; Jonas and Izaurralde, 2015). eIF4A1 and eIF4A2 are replaced by miRISC complex to inhibit translation initiation (Fukao et al., 2014; Fukaya et al., 2014). A major question related to miRNAmediated translational repression is the site at which translational repression takes place although polysome-association is typically correlated with translational repression (Maroney et al., 2006). miRISCs appear to exist in high molecular weight complexes (HMWCs, e.g., polyribosomes) as well as low-molecular weight complexes (LMWCs, e.g., non-polysomal mRNPs) (La Rocca et al., 2015). Apparently, miRISC complexes exist in LMWCs in most healthy tissues while they exist in HMWCs in cell lines. Interestingly, in resting $\mathrm{T}$ cells, miRISCs are not actively engaged in target repression as they exist in LMWCs. Upon $\mathrm{T}$ cell activation, miRISCs are geared toward HMWCs (La Rocca et al., 2015). Messenger ribonucleoprotein complexes are dynamic structures that are formed from non-translating mRNAs through the binding of a number of proteins that determine the fate of mRNAs, e.g., translation, localization or turnover (Buchan, 2014). mRNPs are not merely formed as a consequence of polysome dissociation. Rather, the assembly of a fraction of it involves an orderly scanning and target site recognition by miRISC followed by the recruitment of additional factors such as the CCR4-NOT complex (Wu et al., 2017). Thus, as certain mRNP granules are formed as a result of polysome disassembly (e.g., under stress conditions), some could be formed de novo from non-translating mRNAs. Dynamics changes in the polysomal versus non-polysomal association of miRISCs suggests that the action site for each miRISC could be different based on its target, cell type or phenotypic context.

An in-dept analysis of small RNA profiling, preferably in conjuction with proteomics, based on their association with sucrose density fractions and comparison of such profiles between different conditions (e.g., different developmental stages or health versus disease) may provide insight into the potential role of polysomes in coordinating miRISC silencing activity. Göktaş et al. (2017) took advantage of 
the existence of extensive post-transcriptional gene regulatory networks in Drosophila melanogaster embryos to track the intracellular small RNA dynamics. Sucrose density fractionation of polysomes followed by small RNA profiling revealed (1) the presence of certain miRNAs non-selectively throughout all fractions; (2) the abundance of certain miRNAs in either polysomal or non-polysomal fractions; (3) the transition of certain miRNAs from polysomal fractions to non-polysomal ones or vice versa following the maternal-to-zygotic transition (Coşacak et al., 2018). A side-by-side analysis of small RNAs in total RNA and fractionated RNAs showed the dynamic re-distribution of miRNA in the cytoplasm irrespective of a potential change in the transcriptional output. Molotski and Soen (2012) observed a similar differential polysomal occupancy of miRNAs between human embryonic stem cells and foreskin fibroblast cells (Molotski and Soen, 2012). Even more interestingly, differential polysomal association of miRNAs was reported to involve the formation of diverse miRNA effector complexes regulated by extracellular signals (Wu et al., 2013). One interpretation of this finding is that the stimulus-mediated switch from a polysomal to a nonpolysomal miRISC state may result in the formation of different effectors. Such a scenario is possible, for example, when different complexes are formed during de-repression from miRNA-mediated down-regulation (Orang et al., 2014). Then, the remaining question is, considering the polysomal and non-polysomal sites, which one is the actual site of action and which one the site of relief? One caveat of small RNA profiling approaches is that not all miRNAs or AGO proteins may be bound to each other, suggesting that miRNAs may be bound to their targets in the absence of AGO proteins (Wang et al., 2009; Janas et al., 2012). One should be careful in the intepretation of miRNA location when using RNAseq data to localize functionally active miRISC after subcellular fractionation. Thus, the quantitation of all existing miRNAs could not necessarily represent the functional miRISC complexes. AGO-bound miRNAs should be analyzed in any cellular sub-compartments to isolate potentially functional miRISC complexes, avoiding merely mRNA-bound, AGO-free miRNAs.

An interesting question regarding miRISC localization is how various miRISCs are assembled and cargoed in a selective manner to polysomal or non-polysomal sites. There are several miRISC accessory proteins that may modulate the intracytoplasmic fate of miRISCs (Krol et al., 2010). For example, HSP90 is a crucial regulator of $\mathrm{AGO} 2$ localization in non-polysomal foci such as PBs and SGs (Pare et al., 2009). Also, AGO2 post-translational modifications, such as hydroxylation or phosphorylation, may modulate the localization of miRISCs in PBs (Qi et al., 2008; Zeng et al., 2008). It is unknown at this point whether specific intracytoplasmic localization of miRISCs is associated with unequal target abundance in the cytoplasm. Although Coşacak et al. (2018) did not find any correlation between target abundance and miRNA re-arrangement, Molotski and Soen (2012) reported the significance of the seed sequence in the polysome occupancy (Molotski and Soen, 2012; Coşacak et al., 2018). Along the same line, target-dependent biogenesis of miR-122 during stress reversal has been reported in HEK293 cells (Bose and Bhattacharyya, 2016). Thus, it needs to be resolved whether it is the mRNA target location that determines the miRISC location or vice versa. Assuming that the switch between polysomal and non-polysomal fractions under two different phenotypes is because of selective trafficking of target mRNAs (not because of the difference in mRNA identity), an intracellular or extracellular stimulus should be responsible for re-localization of miRISCs. Such a scenario could be facilitated through post-translational modification of protein components or posttranscriptional editing of RNA component of RISC. Indeed, AGO2 phosphorylation at $\mathrm{S} 387$ results in its re-localization to $\mathrm{PB}$, favoring translational repression (Horman et al., 2013).

\section{CONCLUDING REMARKS}

miRISC complexes are distributed throughout the cell, both in the nucleus and cytoplasm depending on the cell type and cellular phenotype. However, more evidence exists for the involvement of $\mathrm{PBs}$ in $\mathrm{AGO} 2$-mediated regulation of miRISC activity. Interestingly, the cytoplasmic location of miRISCs appears to correlate with their fate. For example, ER harbors miRISCs, which appear to regulate the translation of mRNAs destined for ER and golgi while $\mathrm{P}$ bodies house miRISCs associated with mRNAs targeted for degradation. An interesting observation from recent studies is the dynamic changes in the localization of miRISCs between polysomal and non-polysomal (e.g., SGs or P bodies) structures. Although small RNA profiling following cytoplasmic fractionation provides some indirect evidence for such re-arrangement of miRISC complexes, more direct evidence would require the tracing of labeled miRNAs under two different states (e.g., two development states or health states) to eliminate the target heterogeneity as the potential cause of re-localization. More importantly, it begs for more research to delineate the protein and/or miRNA components of miRISCs that are critical for shuffling miRISCs between polysomal and non-polysomal complexes as part of miRISC regulation.

\section{AUTHOR CONTRIBUTIONS}

BA conceived, designed, and wrote the paper. İE participated in designing, revising, and coordination. All authors reviewed and approved the final version.

\section{FUNDING}

The miRNA research in the non-coding RNA Lab (BA) was supported by the Scientific and Technical Research Council of Turkey (TUBITAK 104T144 to BA).

\section{ACKNOWLEDGMENTS}

BA thanks all past and current members of the Non-coding RNA Laboratory for their contribution to the miRNA research. 


\section{REFERENCES}

Aizer, A., Kalo, A., Kafri, P., Shraga, A., Ben-Yishay, R., Jacob, A., et al. (2014). Quantifying mRNA targeting to P-bodies in living human cells reveals their dual role in mRNA decay and storage. J. Cell Sci. 127, 4443-4456. doi: 10.1242/jcs. 152975

Anderson, P., and Kedersha, N. (2008). Stress granules: the Tao of RNA triage. Trends Biochem. Sci. 33, 141-150. doi: 10.1016/j.tibs.2007.12.003

Barrey, E., Saint-Auret, G., Bonnamy, B., Damas, D., Boyer, O., and Gidrol, X. (2011). Pre-microRNA and mature microRNA in human mitochondria. PLoS One 6:e20220. doi: 10.1371/journal.pone.0020220

Bartel, D. P. (2018). Metazoan microRNAs. Cell 173, 20-51. doi: 10.1016/j.cell. 2018.03.006

Bartel, D. P., and Chen, C. Z. (2004). Micromanagers of gene expression: the potentially widespread influence of metazoan microRNAs. Nat. Rev. Genet. 5 , 396-400.

Bazzini, A. A., Lee, M. T., and Giraldez, A. J. (2012). Ribosome profiling shows that miR-430 reduces translation before causing mRNA decay in zebrafish. Science 336, 233-237. doi: 10.1126/science.1215704

Béthune, J., Artus-Revel, C. G., and Filipowicz, W. (2012). Kinetic analysis reveals successive steps leading to miRNA-mediated silencing in mammalian cells. EMBO Rep. 13, 716-723. doi: 10.1038/embor.2012.82

Bhattacharyya, S. N., Habermacher, R., Martine, U., Closs, E. I., and Filipowicz, W. (2006). Relief of microRNA-mediated translational repression in human cells subjected to stress. Cell 125, 1111-1124.

Bose, M., and Bhattacharyya, S. N. (2016). Target-dependent biogenesis of cognate microRNAs in human cells. Nat. Commun. 7:12200. doi: 10.1038/ ncomms 12200

Buchan, J. R. (2014). mRNP granules. Assembly, function, and connections with disease. RNA Biol. 11, 1019-1030. doi: 10.4161/15476286.2014. 972208

Catalanotto, C., Cogoni, C., and Zardo, G. (2016). MicroRNA in control of gene expression: an overview of nuclear functions. Int. J. Mol. Sci. 17:E1712.

Chantarachot, T., and Bailey-Serres, J. (2018). Polysomes, stress granules, and processing bodies: a dynamic triumvirate controlling cytoplasmic mRNA fate and function. Plant Physiol. 176, 254-269.

Chendrimada, T. P., Gregory, R. I., Kumaraswamy, E., Norman, J., Cooch, N., Nishikura, K., et al. (2005). TRBP recruits the dicer complex to Ago2 for microRNA processing and gene silencing. Nature 436, 740-744.

Chu, C. Y., and Rana, T. M. (2006). Translation repression in human cells by microRNA-induced gene silencing requires RCK/p54. PLoS Biol. 4:e210. doi: 10.1371/journal.pbio.0040210

Coşacak, M. I., Yiğit, H., Kizil, C., and Akgül, B. (2018). Re-arrangements in the cytoplasmic distribution of small rnas following the maternal-tozygotic transition in Drosophila Embryos. Genes 9:82. doi: 10.3390/genes 9020082

Eichhorn, S. W., Guo, H., McGeary, S. E., Rodriguez-Mias, R. A., Shin, C., Baek, D., et al. (2014). mRNA destabilization is the dominant effect of mammalian microRNAs by the time substantial repression ensues. Mol. Cell. 56, 104-115. doi: 10.1016/j.molcel.2014.08.028

Filipowicz, W., Bhattacharyya, S. N., and Sonenberg, N. (2008). Mechanisms of post-transcriptional regulation by microRNAs: are the answers in sight? Nat. Rev. Genet. 9, 102-114. doi: 10.1038/nrg2290

Fukao, A., Mishima, Y., Takizawa, N., Oka, S., Imataka, H., Pelletier, J., et al. (2014). MicroRNAs trigger dissociation of eIF4AI and eIF4AII from target mRNAs in humans. Mol. Cell. 56, 79-89. doi: 10.1016/j.molcel.2014.09.005

Fukaya, T., Iwakawa, H. O., and Tomari, Y. (2014). MicroRNAs block assembly of eIF4F translation initiation complex in Drosophila. Mol. Cell. 56, 67-78. doi: 10.1016/j.molcel.2014.09.004

Gallo, C. M., Munro, E., Rasoloson, D., Merritt, C., and Seydoux, G. (2008). Processing bodies and germ granules are distinct RNA granules that interact in C. elegans embryos. Dev. Biol. 323, 76-87. doi: 10.1016/j.ydbio.2008. 07.008

Ghosh, S., Bose, M., Ray, A., and Bhattacharyya, S. N. (2015). Polysome arrest restricts miRNA turnover by preventing exosomal export of miRNA in growthretarded mammalian cells. Mol. Biol. Cell 26, 1072-1083. doi: 10.1091/mbc.E1411- 1521
Gibbings, D. J., Ciaudo, C., Erhardt, M., and Voinnet, O. (2009). Multivesicular bodies associate with components of miRNA effector complexes and modulate miRNA activity. Nat. Cell Biol. 11, 1143-1149. doi: 10.1038/ncb1929

Göktaş, Ç, Yigit, H., Cosacak, M. I, and Akgul, B. (2017). Differentially expressed tRNA-derived small RNAs Co-sediment primarily with nonpolysomal fractions in Drosophila. Genes 8:333. doi: 10.3390/genes8110333

Griffiths-Jones, S., Grocock, R. J., Van Dongen, S., Bateman, A., and Enright, A. J. (2006). miRBase: microRNA sequences, targets and gene nomenclature. Nucleic Acids Res. 34, D140-D144.

Guo, H., Ingolia, N. T., Weissman, J. S., and Bartel, D. P. (2010). Mammalian microRNAs predominantly act to decrease target mRNA levels. Nature 466, 835-840. doi: 10.1038/nature09267

Horman, S. R., Janas, M. M., Litterst, C., Wang, B., MacRae, I. J., Sever, M. J., et al. (2013). Akt-mediated phosphorylation of argonaute 2 downregulates cleavage and upregulates translational repression of MicroRNA targets. Mol. Cell. 50, 356-367. doi: 10.1016/j.molcel.2013.03.015

Hubstenberger, A., Courel, M., Benard, M., Souquere, S., Ernoult-Lange, M., Chouaib, R., et al. (2017). P-body purification reveals the condensation of repressed mRNA regulons. Mol. Cell. 68, 144-157. doi: 10.1016/j.molcel.2017. 09.003

Iwasaki, S., Kobayashi, M., Yoda, M., Sakaguchi, Y., Katsuma, S., Suzuki, T., et al. (2010). Hsc70/Hsp90 chaperone machinery mediates ATP-dependent RISC loading of small RNA duplexes. Mol. Cell. 39, 292-299. doi: 10.1016/j.molcel. 2010.05.015

Janas, M. M., Wang, B., Harris, A. S., Aguiar, M., Shaffer, J. M., Subrahmanyam, Y. V., et al. (2012). Alternative RISC assembly: binding and repression of microRNA-mRNA duplexes by human Ago proteins. RNA 18, 2041-2055. doi: 10.1261/rna.035675.112

Janas, T., Janas, M. M., Sapoń, K., and Janas, T. (2015). Mechanisms of RNA loading into exosomes. FEBS Lett. 589, 1391-1398.

Jeffries, C. D., Fried, H. M., and Perkins, D. O. (2011). Nuclear and cytoplasmic localization of neural stem cell microRNAs. RNA 17, 675-686. doi: 10.1261/rna. 2006511

Jian-You, L., Li-Ming, M., Yan-Hua, G., Yu-Chan, Z., Hui, Z., Peng, S., et al. (2010). Deep sequencing of human nuclear and cytoplasmic small RNAs reveals an unexpectedly complex subcellular distribution of miRNAs and tRNA 30 trailers. PLoS One 5:e10563. doi: 10.1371/journal.pone.0010563

Jin, P., Zarnescu, D. C., Ceman, S., Nakamoto, M., Mowrey, J., Jongens, T. A., et al. (2004). Biochemical and genetic interaction between the fragile X mental retardation protein and the microRNA pathway. Nat. Neurosci. 7, 113-117.

Jonas, S., and Izaurralde, E. (2015). Towards a molecular understanding of microRNA-mediated gene silencing. Nat. Rev. Genet. 16, 421-433. doi: 10.1038/ $\operatorname{nrg} 3965$

Kiebler, M. A., and Bassell, G. J. (2006). Neuronal RNA granules: movers and makers. Neuron 51, 685-690.

Kim, J., Krichevsky, A., Grad, Y., Hayes, G. D., Kosik, K. S., Church, G. M., et al. (2004). Identification of many microRNAs that copurify with polyribosomes in mammalian neurons. Proc. Natl. Acad. Sci. U.S.A. 101, 360-365.

Kim, Y. J., Maizel, A., and Chen, X. (2014). Traffic into silence: endomembranes and post-transcriptional RNA silencing. EMBO J. 33, 968-980. doi: 10.1002/ embj.201387262

Kren, B. T., Wong, P., Sarver, A., Zhang, X., Zeng, Y., and Steer, C. J. (2009). MicroRNAs identified in highly purified liver-derived mitochondria may play a role in apoptosis. RNA Biol. 6, 65-72.

Krichevsky, A. M., and Kosik, K. S. (2001). Neuronal RNA granules: a link between RNA localization and stimulation-dependent translation. Neuron 32, 683-696.

Krol, J., Loedige, I., and Filipowicz, W. (2010). The widespread regulation of microRNA biogenesis, function and decay. Nat. Rev. Genet. 11, 597-610. doi: $10.1038 / \mathrm{nrg} 2843$

La Rocca, G., Olejniczak, S. H., González, A. J., Briskin, D., Vigidal, J. A., Spraggon, L., et al. (2015). In vivo, Argonaute-bound microRNAs exist predominantly in a reservoir of low molecular weight complexes not associated with mRNA. Proc. Natl. Acad. Sci. U.S.A. 112, 767-772. doi: 10.1073/pnas. 1424217112

Lee, R. C., Feinbaum, R. L., and Ambros, V. (1993). The C. elegans heterochromic gene lin-4 encodes small RNAs with antisense complementary to lin-14. Cell 75, 843-854. 
Lee, Y., Ahn, C., Han, J., Choi, H., Kim, J., Yim, J., et al. (2003). The nuclear RNase III Drosha initiates microRNA processing. Nature 425, 415-419.

Lee, Y., Kim, M., Han, J., Yeom, K.-H., Lee, S., and Baek, S. H. (2004). MicroRNA genes are transcribed by RNA polymerase II. EMBO J. 23, 4051-4060.

Lerner, R. S., Seiser, R. M., Zheng, T., Lager, P. J., Reedy, M. C., Keene, J. D., et al. (2003). Partitioning and translation of mRNAs encoding soluble proteins on membrane-bound ribosomes. RNA 9, 1123-1137.

Leung, A. K. L. (2015). The whereabouts of microRNA actions: cytoplasm and beyond. Trends Cell Biol. 25, 601-610. doi: 10.1016/j.tcb.2015.07.005

Leung, A. K. L., Calabrese, J. M., and Sharp, P. A. (2006). Quantitative analysis of Argonaute protein reveals microRNA-dependent localization to stress granules. Proc. Natl. Acad. Sci. U.S.A. 103, 18125-18130.

Leung, A. K. L., and Sharp, P. A. (2013). Quantifying Argonaute proteins in and out of GW/P-bodies: implications in microRNA Activities. Adv. Exp. Med. Biol. 768, 165-182. doi: 10.1007/978-1-4614-5107-5_10

Li, P., Jiao, J., Gao, G., and Prabhakar, B. S. (2012). Control of mitochondrial activity by miRNAs. J. Cell. Biochem. 113, 1104-1110. doi: 10.1002/jcb.24004

Li, S., Liu, L., Zhuang, X., Yu, Y., Liu, X., Cui, X., et al. (2013). MicroRNAs inhibit the translation of target mRNAs on the endoplasmic reticulum in Arabidopsis. Cell 153, 562-574. doi: 10.1016/j.cell.2013.04.005

Liu, H., Lei, C., He, Q., Pan, Z., Xiao, D., and Tao, Y. (2018). Nuclear functions of mammalian MicroRNAs in gene regulation, immunity and cancer. Mol. Cancer 17:64.

Liu, J., Valencia-Sanchez, M. A., Hannon, G. J., and Parker, R. (2005). MicroRNAdependent localization of targeted mRNAs to mammalian P-bodies. Nat. Cell Biol. 7, 719-723.

Lund, E., Güttinger, S., Calado, A., Dahlberg, J. E., and Kutay, U. (2004). Nuclear export of microRNA precursors. Science 303, 95-98.

Maroney, P. A., Yu, Y., Fisher, J., and Nilsen, T. W. (2006). Evidence that microRNAs are associated with translating messenger RNAs in human cells. Nat. Struct. Mol. Biol. 13, 1102-1107.

Meister, G., Landthaler, M., Patkaniowska, A., Dorsett, Y., Teng, G., and Tuschl, T. (2004). Human Argonaute2 mediates RNA cleavage targeted by miRNAs and siRNAs. Mol. Cell. 15, 185-197.

Molotski, N., and Soen, Y. (2012). Differential association of microRNAs with polysomes reflects distinct strengths of interactions with their mRNA targets. RNA 18, 1612-1623. doi: 10.1261/rna.033142.112

Moretti, F., Kaiser, C., Zdanowicz-Specht, A., and Hentze, M. W. (2012). PABP and the poly(A) tail augment microRNA repression by facilitated miRISC binding. Nat. Struct. Mol. Biol. 19, 603-608. doi: 10.1038/nsmb.2309

Nelson, P. T., Hatzigeorgiou, A. G., and Mourelatos, Z. (2004). miRNP:mRNA association in polyribosomes in a human neuronal cell line. RNA 10, 387-394.

Nottrott, S., Simard, M. J., and Richter, J. D. (2006). Human let-7a miRNA blocks protein production on actively translating polyribosomes. Nat. Struct. Mol. Biol. $13,1108-1114$.

Olsen, P. H., and Ambros, V. (1999). The lin-4 regulatory RNA controls developmental timing in Caenorhabditis elegans by blocking LIN-14 protein synthesis after the initiation of translation. Dev. Biol. 216, 671-680.

Orang, A. V., Safaralizadeh, R., and Kazemzadeh-Bavili, M. (2014). Mechanisms of miRNA-mediated gene regulation from common downregulation to mRNA-specific upregulation. Int. J. Genomics 2014:970607. doi: 10.1155/2014/ 970607

Pare, J. M., Tahbaz, N., Lopez-Orozco, J., LaPointe, P., Lasko, P., and Hobman, T. C. (2009). Hsp90 regulates the function of argonaute 2 and its recruitment to stress granules and P-bodies. Mol. Biol. Cell 20, 3273-3284. doi: 10.1091/mbc. E09-01-0082

Petersen, C. P., Bordeleau, M. E., Pelletier, J., and Sharp, P. A. (2006). Short RNAs repress translation after initiation in mammalian cells. Mol. Cell. 21, 533-542.

Pillai, R. S., Bhattacharyya, S. N., Artus, C. G., Zoller, T., Cougot, N., Basyuk, E., et al. (2005). Inhibition of translational initiation by let-7 microRNA in human cells. Science 309, 1573-1576.
Protter, D. S., and Parker, R. (2016). Principles and properties of stress granules. Trends Cell Biol. 26, 668-679. doi: 10.1016/j.tcb.2016. 05.004

Qi, H. H., Onqusaha, P. P., Myllyharju, J., Cheng, D., Pakkanen, O., Shi, Y., et al. (2008). Prolyl 4-hydroxylation regulates argonaute 2 stability. Nature 455 , 421-424. doi: $10.1038 /$ nature 07186

Reid, D. W., and Nicchitta, C. V. (2015). Diversity and selectivity in mRNA translation on the endoplasmic reticulum. Nat. Rev. Mol. Cell Biol. 16, 221-231. doi: $10.1038 / \mathrm{nrm} 3958$

Ron, D., and Walter, P. (2007). Signal integration in the endoplasmic reticulum unfolded protein response. Nat. Rev. Mol. Cell Biol. 8, 519-529.

Sahoo, M. R., Gaikwad, S., Khuperkar, D., Ashok, M., Helen, M., Yadav, S. K., et al. (2017). Nup358 binds to AGO proteins through its SUMO-interacting motifs and promotes the association of target mRNA with miRISC. EMBO Rep. 18, 241-263. doi: 10.15252/embr.201642386

Schwartz, T. U. (2007). Origins and evolution of cotranslational transport to the ER. Adv. Exp. Med. Biol. 607, 52-60.

Sheth, U., and Parker, R. (2003). Decapping and decay of messenger RNA occur in cytoplasmic processing bodies. Science 300, 805-808.

Tu, C. P., and Akgül, B. (2005). Drosophila glutathione S-transferases. Methods Enzymol. 401, 204-226.

Wang, B., Li, S., Qi, H. H., Chowdhury, D., Shi, Y., and Novina, C. D. (2009). Distinct passenger strand and mRNA cleavage activities of human Argonaute proteins. Nat. Struct. Mol. Biol. 16, 1259-1266. doi: 10.1038/ns mb.1712

Wightman, B., Ha, I., and Ruvkun, G. (1993). Posttranscriptional regulation of the heterochronic gene lin-14 by lin- 4 mediates temporal pattern formation in C. elegans. Cell 75, 855-862.

Wu, E., Vashisht, A. A., Chapat, C., Flamand, M. N., Cohen, E., and Sarov, M. (2017). A continuum of mRNP complexes in embryonic microRNAmediated silencing. Nucleic Acids Res. 45, 2081-2098. doi: 10.1093/nar/ gkw872

Wu, P. H., Isaji, M., and Carthew, R. W. (2013). Functionally diverse microRNA effector complexes are regulated by extracellular signaling. Mol. Cell. 52, 113123. doi: $10.1016 /$ j.molcel.2013.08.023

Yang, J. S., and Lai, E. C. (2011). Alternative miRNA biogenesis pathways and the interpretation of core miRNA pathway mutants. Mol. Cell 43, 892-903. doi: 10.1016/j.molcel.2011.07.024

Yekta, S., Shih, I. H., and Bartel, D. P. (2004). MicroRNA-directed cleavage of HOXB8 mRNA. Science 304, 594-596.

Zalfa, F., Achsel, T., and Bagni, C. (2006). mRNPs, polysomes or granules: FMRP in neuronal protein synthesis. Curr. Opin. Neurobiol. 16, 265-269.

Zeng, Y., Sankala, H., Zhang, X., and Graves, P. R. (2008). Phosphorylation of Argonaute 2 at serine-387 facilitates its localization to processing bodies. Biochem. J. 413, 429-436. doi: 10.1042/BJ20 080599

Zhang, L., Ding, L., Cheung, T. H., Dong, M. Q., Chen, J., Sewell, A. K., et al. (2007). Systematic identification of miRISC proteins, miRNAs, and their mRNA targets in C. Elegans by their interactions with GW182 family proteins AIN-1 and AIN-2. Mol. Cell 28, 598-613.

Conflict of Interest Statement: The authors declare that the research was conducted in the absence of any commercial or financial relationships that could be construed as a potential conflict of interest.

Copyright (c) 2018 Akgül and Erdoğan. This is an open-access article distributed under the terms of the Creative Commons Attribution License (CC BY). The use, distribution or reproduction in other forums is permitted, provided the original author(s) and the copyright owner(s) are credited and that the original publication in this journal is cited, in accordance with accepted academic practice. No use, distribution or reproduction is permitted which does not comply with these terms. 